\title{
Cultural aspects of vaginismus therapy: a case series of Arab-Muslim patients
}

\author{
Yosra Zgueb ${ }^{1,2}$, Uta Ouali ${ }^{1,2 *}$, Radhouane Achour ${ }^{2,3}$, Rabaa Jomli ${ }^{1,2}$ and \\ Fethi Nacef $^{1,2}$ \\ ${ }^{1}$ Department of Psychiatry A, Razi Hospital La Manouba, Tunisia \\ ${ }^{2}$ Faculty of Medicine, University of Tunis El-Manar, Tunis, Tunisia \\ ${ }^{3}$ Emergency Department of Gynecology and Obstetrics, Centre of Maternity and Neonatology of Tunis, \\ Tunisia
}

Received 28 February 2018; Accepted 8 July 2018

\begin{abstract}
Vaginismus in one of the most frequent causes of non-consummation of marriage, and of infertility, in Arab-Muslim societies. Cognitive behavioural therapy (CBT) proved to be effective, but it is important to consider the cultural context of the patient attending CBT for vaginismus. The aim of our study was therefore to draw attention to the belief systems and behaviours linked to female sexuality and couple relationship in the Arab-Muslim culture. We present a series of four patients representative of the local culture and show how treatment strategies were adapted to fit these behaviours and belief systems, as well as environmental factors. We found that excessive closeness of family members, allowing the family to be intrusive and exercising pressure on the couple, a strict education which highly values virginity, transmits fear of 'the male' and fear of sex, and which links sex with pain, were the common denominator of all patients of our case series. We adapted the classical CBT strategies for vaginismus to our cultural context. The educational component was enlarged. Cognitive techniques were used to modify specific traditional beliefs. The integration of the family, and not only of the partner, into the treatment process proved uniquely beneficial for the patients.
\end{abstract}

Keywords: cognitive behaviour therapy, culturally sensitive, Muslim, women's issues, family, anxiety

\section{Introduction}

Vaginismus is a female sexual dysfunction according to the Diagnostic and Statistical Manual of Mental Disorders (DSM IV-TR), and is defined as a recurrent or persistent involuntary spasm of the musculature of the outer third of the vagina, which interferes

\footnotetext{
*Author for correspondence: Uta Ouali, Department of Psychiatry A, Hôpital Razi, Cité des Orangers, 2010 La Manouba, Tunisia (email: uta.ouali@gmail.com).
} 
with sexual intercourse (American Psychiatric Association, 2000). Vaginismus, in DSM-5, was integrated into a new diagnostic category termed Genito-Pelvic Pain/Penetration Disorder, covering a wider range of pain and penetration problems (American Psychiatric Association, 2013). While the prevalence of vaginismus is $1-7 \%$ worldwide, the ratio has been documented to increase up to 5-17\% in clinical settings (Lahaie et al., 2010). In Arab and Muslim countries, it is the most frequent disorder accounting for unconsummated marriage (UCM) (Zargooshi, 2000; Addar, 2004). Thus, several studies have found vaginismus to be the cause of UCM in 20-67\% of couples (Özdemir et al., 2008; Jindal and Jindal, 2010). The prevalence of vaginismus in UCM in Tunisia was found to be $40 \%$ (Mhiri et al., 2013).

Vaginismus can lead to dyspareunia, infertility and sexual dysfunction in both partners with often secondary erectile dysfunction in the male partner (Klein et al., 2015), and therefore has a severe impact on the quality of the marital relationship. The treatment of vaginismus is mostly psychological, and cognitive behavioural therapy (CBT) has proved to be effective (Kabakci and Batur, 2003; Mousavi Nasab and Farnoosh, 2003; van Lankveld et al., 2006). It consists essentially of two techniques: sexual education and hierarchic exposure.

In Tunisia, as in many other Arab-Muslim societies, it is through marriage that couples can have a legal sexual relationship, and virginity before marriage is highly valued. Sexuality is still a 'taboo' in large parts of the population, likewise to consult for sexual difficulties.

Although many immigrants of Arab-Muslim culture or religion to 'Western' countries rapidly embrace the culture of their host society, beliefs and attitudes learned in childhood or linked to religion tend to persist throughout adulthood. Several social risk factors have been identified for the development of vaginismus: for example the way sexuality is taught in families and schools, or the way it is viewed by religion (van Lankveld et al., 2010). Therefore, it seems important to consider the cultural context of the patient attending CBT. This consideration helps to understand the expectations of the patients and of their families, underlying belief systems concerning the disorder, and specific attitudes concerning psychotherapy. It is also beneficial for the therapeutic relationship and crucial in tailoring the treatment approach to the individual patient.

\section{Aims and methods}

The aim of our study was therefore to draw attention to the belief systems and behaviours linked to female sexuality and couple relationship in the Arab-Muslim culture. We present a series of four patients representative of this culture and show how treatment strategies were adapted to fit these behaviours, belief systems and environmental factors.

In the case description, we intentionally focused on the cultural aspects of conceptualization and therapy and therefore chose to shorten or omit other (more generic) parts. Our intention was to show, through the cases of the four patients, a whole range of culture-related problems and how to tackle them rather than describing one case in detail. For each patient, we start by presenting the biography, a brief case history and the aim of the patient. We then present the functional analysis through the SORC (stimulus - organism - response - consequences) model. Quantitative assessment was done by the Beck Depression Inventory II and the State and Trait Anxiety Inventory. Finally, we present a brief overview of the therapy as well as its outcome. 


\section{Case series}

Patient 1, a 25-year-old married university student, consulted a gynaecologist after 9 months of marriage with the desire to have a child. However, the gynaecologist was not able to proceed to a gynaecological examination because of vaginismus. The patient was therefore referred to a psychiatrist for psychological treatment.

The patient did not have any history of aggression or sexual abuse. However, she emphasized that her strict religious upbringing and the statements of her married sisters who described the pain of defloration as horrible and unbearable had a great impact on her.

The entire nuclear family and family-in-law knew about the patient's difficulties to conceive and the fact that she was in psychotherapy for this reason. Her mother-in-law was very intrusive and would even accompany her to the therapy sessions and ask the therapist whether this was a curable condition. The mother-in-law was worried about the status and reputation of her son within the larger family structure.

The patient clearly stated that her main aim of the therapy was to conceive a child. Functional analysis revealed that each time the husband attempted penetration, she felt anxious, panicked, had palpitations, and contracted her thighs. She anticipated unbearable pain, the reason for which she avoided contact with her husband.

For treatment to succeed, the family had to be integrated into the treatment process. The couple as well as the mother-in-law received sexual education with special attention to worries about fertility. Cognitive techniques were employed to modify her fear of defloration. The patient then had graded exposure therapy, first in imagination, later in vivo. The patient reported a $70 \%$ decrease in anxiety, and was able to have sexual intercourse. She became pregnant after 15 sessions of psychotherapy.

Patient 2, a 30-year-old teacher, consulted after 8 months of marriage. She had been very reluctant to consult a psychiatrist, and she only accepted the referral after a defloration in gynaecology had not improved her vaginismus symptoms. The patient had a strict and very conservative religious upbringing which also gave her the belief that men were superior to women. In her marriage she felt guilty because, as a Muslim woman, she was supposed to satisfy her husband in every way. Her partner was a very kind and caring person, who avoided sexual intercourse as 'he did not want to hurt her', psychologically as well as physically. Both the patient and her partner had not had any sexual education during childhood or adolescence.

The aim of the patient was to have a satisfying sex life. Assessment showed that each time the husband attempted physical affection, she felt anxious, guilty, and retreated. A CBT couple treatment was indicated. Psycho-education helped both partners to acquire basic knowledge in anatomy and physiology, as well as to understand the psycho-sexual differences and complementarities between men and women. The patient had individual sessions of cognitive therapy to modify beliefs pertaining to her role as a wife. The main intermediate belief discussed with the patient, was: 'If I do not satisfy my husband sexually, I am guilty and God will punish me'. With the help of socratic questioning, we identified evidence that supports this idea, and evidence against this idea, and we helped her to realize that her worst fears were unlikely to come true. In addition, we arranged for the patient to ask the opinion of an imam (which is a person who leads prayers at a mosque and preaches) concerning her personal responsibility in the vaginismus symptoms and whether this was a reason for God to punish her. The imam explained that she was not guilty 'as she had the will to satisfy her husband, but that she suffered from a disorder, and God does not punish people for medical 
or psychiatric disorders which are stronger than the person'. She was able to elaborate the following alternative thought: 'It is true that I do not satisfy my husband sexually as I wish to, but I have a disorder and I am doing my best to get better'. This thought allowed her to feel less guilty and greatly facilitated the following exposure therapy. The husband played a major role in therapy: he respected the therapeutic agreement during all phases of the exposure. After 12 sessions, depression and anxiety scores decreased by 50\%, and the couple managed to have sexual intercourse.

Patient 3 was a 35 -year-old judge, who was married and a mother of two children. She was referred by a gynaecologist after her childbirth for her refusal of vaginal delivery. In fact, the patient had conceived her children by superficial sexual contact without penetration.

As a child, the patient had a strict religious education, whose main goal was to protect her virginity. For this reason, the patient had a 'tasfih', a traditional magic ritual supposed to make the girl indeflorable, which is 'removed' before marriage. It is not related to any form of female genital mutilation, as no physical harm is done to the girl's genitals.

The patient stated that she did not feel any sexual desire nor any pleasure during sexuality. The patient said: 'I am like a stone wall, I feel nothing'.

The aim of the patient was to have complete sexual intercourse. Functional analysis showed that when the husband tried to spread her thighs, she panicked, trembled, and thought she was impenetrable and therefore anticipated pain. Both partners received sexual education, insisting on the necessity of preliminaries.

Individual therapy was centred on the modification of traditional beliefs about virginity and the 'tasfih' ritual. Couple therapy was centred on sensate focus exercises including the discovery of body touch initially without the pressure of any penetration. The patient reported a gradual improvement of anxiety. After 20 sessions, the couple was able to have complete sexual intercourse with improvement in sexual desire of the patient.

Patient 4 was a 26-year-old housewife, originating from a rural area. Her education was mainly focused on the necessity to stay virgin until marriage, and to keep away from men, because 'they are all dangerous'. The night of her marriage, although she was anxious about penetration and defloration, she was able to have sexual intercourse with her husband. The patient believed that, after defloration, the husband was not supposed to touch her for three nights, because this might hurt her and induce bleeding. However, the husband did not accept this belief and her refusal of sex, and he raped her the same night. After this trauma, a sexual 'relationship' was only possible through repeated rapes. The family of the patient was aware of these rapes but accepted them, as, they stated 'it was the husband's right to have sexual intercourse with his wife'. The patient was admitted to psychiatric hospital for severe anxiety. Psychiatric examination revealed depressive symptoms. Furthermore, the patient felt deeply guilty about not being 'a good wife' and not 'fulfilling her duty'.

The aim of the patient was to decrease anxiety and guilt towards her husband. Functional analysis revealed that each time the husband approached her for a sexual relationship, she started crying and imagined a scene where the entire floor was covered with her blood. She then screamed and refused any physical contact with the husband, which led the husband to physically contain and rape her.

The patient received anti-depressant treatment and CBT. The husband refused to participate in therapy, as 'sexuality only concerns husband and wife, and it is a taboo to talk about it'. So exposure therapy was started with the patient only; we asked her respectively: to look at herself in the mirror, to touch her body, giving special attention to the genital region, 
to introduce her fingers into the vagina. We further conducted imaginary exposure to the traumatic sexual events. After 12 sessions, the patient was able to return with her husband. She was able to accept sexual intercourse, but without any sexual desire and without orgasm. The patient also benefited from education about the rights of women within a marital relationship. The mother and the sister of the patient were also educated on this subject, and all of them were then able to transmit some of the acquired knowledge to the husband.

\section{Discussion}

In Tunisia as in other Arab Muslim countries, sexuality remains a taboo and a very sensitive subject, so patients do not generally consult directly a sex therapist but gynaecologists, as seen in our case series (Auwad and Hagi, 2012; Muammar et al., 2015).

Time intervals between the onset of vaginismus symptoms and the initial consultation are short compared with Western countries that report a period of several years (Karrouri, 2017). This could be explained by the often excessive closeness of family members, allowing the family or family-in-law to be intrusive. Indeed, close family often exercises pressure on the couple to consummate their marriage shortly after the marriage ceremonies and to conceive a child very rapidly. This is especially true for conservative families, families with little education or a lack of sex education. Indeed, UCM is very rare in developed societies, as there are many opportunities for pre-marital sexual contact (Zargooshi, 2000). In couples with higher educational levels, the family or family-in-law are less involved in the couple relationship, but the weight of culture is still present, as is the case for Patient 3.

Therefore, in traditional Arab-Muslim society, vaginismus could be considered a family problem, rather than the sole problem of a couple. Indeed, the reputation and the honor of the family are very important. This includes the virginity of the bride and procreation to perpetuate the family name. These imperatives authorize especially mothers and mothers-in-law to know all the details of the intimate life of the couple, and even a permissive and passive attitude with regard to women beaten for their vaginismus is accepted (Karrouri, 2017). Although vaginismus is not always a source of infertility, it is necessary to search for it if a delay in conception is noticed (Moller et al., 2015).

Several aetiological factors have been reported in literature as the main causes of vaginismus: lack of sex education, ignorance, guilt about sexuality, fear of pain, histrionic personality traits, perfectionism, low self-esteem with a fear of negative evaluation, and a history of physical or sexual abuse in childhood (van Lankveld et al., 2010). In our case series, sexual abuse was found in one patient (Patient 4), not during childhood but starting right after her wedding. The sexual abuse seemed to have triggered the vaginismus in this already vulnerable patient.

Strict religious education and cultural taboos were cited as aetiological factors of vaginismus by several authors (Ellison, 1968; Reissing et al., 1999). Indeed, a strict education which highly values virginity, transmits fear of 'the male' and fear of sex, and which links sex with pain, is the common denominator of all patients of our case series. There is little place for sensuality and bodily pleasure in the couple relationships, and a sexual relationship is mostly associated with penetration and conception. In Arab-Muslim societies, marriage is considered a social and religious obligation, and the couple must fulfil a role within family and society. This implies having children to perpetuate the family and be a 'good' wife. Sexual desire for men is permitted, but only within the boundaries of marriage. 
From a strict cognitive behavioural point of view, warning messages transmitted by a strict education or family role models can lead to dysfunctional core beliefs related to danger, guilt or perfectionism, or to classical/operant conditioning or socially learned dysfunctional behaviour. Vaginismus could be considered a specific phobia with severe anxiety or panic, provoked by exposure to a specific feared object or situation. When this feared situation is sexual, it can become a fear of vaginal penetration (Reissing et al., 2004; Melzack, 2005). The fear of the sexual situation can be amplified by the fear of pain (Weijmar Schultz et al., 2005). Classical conditioning due to traumatic sexual experiences (which can sometimes be due to the vaginismus itself), as was the case in Patient 4, could trigger or aggravate vaginismus.

'Tasfih', meaning lock-up, is a traditional magic ritual supposed to make the girl indeflorable which is widespread in all Maghreb countries. However, no numbers exist on the frequency of this ritual. Links between tasfih and vaginismus are reported in the literature (Ben Dridi, 2004).

Anthropological studies have been conducted to understand the procedures of 'tasfih' and its perception in the population. Several 'tasfih' techniques have been described (Ben Dridi, 2004). One of the most widespread is the scarification technique: a women specializing in rituals does seven superficial scarifications on the right knee of the girl and dips seven raisins or dates in the blood that comes out of these wounds. Before eating the raisins or dates soaked with blood the girl must say: 'I am a wall and the son of the other is a thread'. This is supposed to 'lock' the girl. The ritual of 'unlocking' is done just before marriage by the same or another women, and the young bride must say: 'I am a thread and the son of the other is a wall'. There is, of course, no anatomical explanation for the 'impenetrability' of the women or the sexual impotence reported by men who tried to have sex with women who have undergone the 'lock-up' ritual. The most plausible explanation is psychological (Ben Dridi, 2004). In terms of cognitive behavioural conceptualization, we suppose that a form of conditioning took place between a situation where penetration would be possible and panic, anxiety and involuntary contraction which is maintained by the belief 'I am a wall' as well as avoidance behaviour.

A variety of interventions have been suggested for the treatment of vaginismus, ranging from sex education to decreasing penetration fear and anxiety. Some therapies include educational gynecological examinations (Flanagan et al., 2015), the application of topical anesthetics (Praharaj et al., 2006), pelvic floor biofeedback (Seo et al., 2005), botulinum toxin injections (Brin and Vapnek, 1997), anxiolytic medication (Plaut and Rach Beisel, 1997), and surgical intervention (Ramli et al., 2012). CBT is the most important intervention, and studies have found it to improve several domains of sexual functioning such as frequency of sexual intercourse, communication about sexuality, sexual satisfaction, avoidance behaviour, and sensuality (Safak Ozturk and Arkar, 2017).

We adapted the classical CBT strategies for vaginismus to our cultural context.

First of all, sexuality is a very intimate subject involving the couple; however, as previously stated, family relationships in traditional Arab-Muslim societies are characterized by excessive closeness, and vaginismus exceeds the limits of the couple to become a family problem. To start, couples and family members closely involved should receive sex education, with information about anatomy, physiology, and the differences between men and women. Choice of terms related to sexuality was sometimes difficult, and we used the terms the couples and families would use in order to avoid any misinterpretation or judgement. 
As was shown through the cases, husbands can be a potential risk factor for vaginismus, through violent or inconsiderate behaviour (case 4). Husbands can also be a source of major support (cases 1-3).

Cognitive therapy is centred on abnormal perception including the 'breaking' of the hymen upon the first attempt of penetration and the awareness that it will be accompanied with pain or bleeding.

Concerning the beliefs about the risks of bleeding and strong pain, we recommended bibliotherapy to literate patients and their families. We chose documents on anatomy and physiology, for example about the arterial irrigation of the vagina and the hymen.

Different cognitive techniques were used to work on the core beliefs about danger and guilt. These were: socratic questioning, finding the evidence for and against a belief, and advantages and disadvantages of holding a belief, as well as de-dramatization. We noticed that a high educational level did not automatically imply that the patient had a thorough sex education. It does not preclude cognitive distortions and false ideas about sex.

Obtaining the opinion of religious leaders or authorities can be very beneficial for therapy, as religious patients tend to trust these authorities and consider them more knowledgeable in the domain of religion than therapists. We generally resort to imams who are known to be sensitive to issues about mental illness and who are able to make patients feel less guilty by referring to the Holy Quran.

It should also be noted that beliefs in 'The Evil Eye' and 'Djinn possession' as causes of mental disorders are very prevalent in Arab-Muslim societies (Rayan and Fawaz, 2017). Therefore, parallel interventions with traditional therapists should be respected as long as they do not interfere negatively with the sex therapy.

Graded exposure therapy is a mainstay of the CBT treatment for patients. However, we noticed that graded insertion of (the men's) fingers with free usage of local anaesthesia and lubricant with vaginal containment was considered by some men as an 'offence' to their masculinity. Therefore, we emphasized the rationale of this technique and specially valued the role of the husband for the success of the method.

Support, patience and empathy were important aspects of the treatment process. Some studies suggest that daily treatment sessions are more efficient, producing more immediate responses (Muammar et al., 2015), and that couples with a duration of unconsummated intercourse of less than 2 years had better outcomes than those with a longer duration (Jeng et al., 2006). These findings seem understandable, but it might in practice prove difficult to install daily treatment sessions.

\section{Main points}

(1) Vaginismus is a common psychosexual problem in many Arab-Muslim countries and is a cause of UCM and infertility. In general, patients do not directly consult a psychotherapist for this problem, and they are more often referred by gynaecologists. It seems that insufficient sexual knowledge is the major potential risk factor to developing this condition.

(2) Special attention should be paid to the cultural and religious aspects of vaginismus in patients with an Arab-Muslim background. First, vaginismus should be considered more of a family problem rather than the sole problem of the couple. Second, even if the patient has a high educational and professional level and might seem 'highly Westernized', 
traditional beliefs, mostly originating in childhood, related to virginity and the traditional or religious role of the wife should be sought for.

(3) CBT of vaginismus in these patients should have a large educational component. Cognitive techniques can be used to modify specific traditional beliefs. The integration of the family, and not only of the partner, into the treatment process could prove uniquely beneficial for these patients.

\section{Acknowledgements}

The authors would like to express their sincere gratitude to the four patients without whom this case study would not have been possible.

\section{Conflicts of interest}

Yosra Zgueb, Uta Ouali, Radhouane Achour, Rabaa Jomli and Fethi Nacef have no conflicts of interest with respect to this publication.

\section{Ethical statement}

We confirm that the authors have abided by the Ethical Principles of Psychologists and Code of Conduct as set out by the American Psychological Association. All patients gave their written informed consent to the publication of their cases.

\section{Financial support}

This research received no specific grant from any funding agency, commercial or not-for-profit sectors.

\section{Suggestions for follow-up reading}

- Okasha A, Maj M (2001). Images in Psychiatry. An Arab Perspective. Cairo: Scientific Book House.

- Kadri N (2010). Manuel d'éducation sexuelle. Casablanca: Le Fennec.

\section{References}

Addar MH (2004). The unconsummated marriage: causes and management. Clinical and Experimental Obstetrics and Gynecology 31, 279-281.

American Psychiatric Association (2000). Diagnostic and Statistical Manual of Mental Disorders, 4th edn.

American Psychiatric Association (2013). Diagnostic and Statistical Manual of Mental Disorders, 5th edn.

Auwad WA, Hagi SK (2012). Female sexual dysfunction: what Arab gynecologists think and know. International Urogynecology Journal 23, 919-927.

Ben Dridi I (2004). Le tasfih en Tunisie. Un rituel de protection de la virginité féminine. L'Harmattan: Paris. 
Brin MF, Vapnek JM (1997). Treatment of vaginismus with botulinum toxin injections. Lancet 349, 252-253.

Ellison C (1968). Psychosomatic factors in the unconsummated marriage. Journal of Psychosomatic Research 12, 61-65.

Flanagan E, Herron KA, O'Driscoll C, Williams AC (2015). Psychological treatment for vaginal pain: does etiology matter? A systematic review and meta-analysis. Journal of Sexual Medicine 12, $3-16$.

Jeng CJ, Wang LR, Chou CS, Shen J, Tzeng CR (2006). Management and outcome of primary vaginismus. Journal of Sex and Marital Therapy 32, 379-387.

Jindal UN, Jindal S (2010). Use by gynecologists of a modified sensate focus technique to treat vaginismus causing infertility. Fertility and Sterility 94, 2393-2395.

Kabakci E, Batur S (2003). Who benefits from cognitive behavioral therapy for vaginismus? Journal of Sex and Marital Therapy 29, 277-288.

Karrouri R (2017). Mariage non consommé et vaginisme: à propos de trois cas Clinique. The Pan African Medical Journal 27, 60.

Klein V, Koops T, Lange C, Briken P (2015). Sexual history of male partners of women with the diagnosis vaginismus. Sexual and Relationship Therapy 30, 376-384.

Lahaie MA, Boyer SC, Amsel R, Khalife S, Binik YM (2010). Vaginismus: a review of the literature on the classification/diagnosis, etiology and treatment. Women's Health (London) 6, 705-719.

Melzack R (2005). Evolution of the neuromatrix theory of pain. The Prithvi Raj Lecture: presented at the third World Congress of World Institute of Pain, Barcelona 2004. Pain Practice 5, 85-94.

Mhiri M, Smaoui W, Bouassida M, Chabchoub K, Masmoudi J, Bahloul A (2013). Unconsummated marriage in the Arab Islamic world: Tunisian experience. Sexologies 22, 103-108.

Moller L, Josefsson A, Bladh M, Lilliecreutz C, Sydsjo G (2015). Reproduction and mode of delivery in women with vaginismus or localised provoked vestibulodynia: a Swedish register-based study. BJOG: An International Journal of Obstetrics and Gynaecology 122, 329-334.

Mousavi Nasab M, Farnoosh Z (2003). Management of vaginismus with cognitive-behavioral therapy, self-finger approach: a study of 70 cases. Iranian Journal of Medical Sciences 28, 69-71.

Muammar T, McWalter P, Alkhenizan A, Shoukri M, Gabr A, Bin AA (2015). Management of vaginal penetration phobia in Arab women: a retrospective study. Annals of Saudi Medecine 35, 120 126.

Özdemir Ö, Şimşek F, Özkardeş S, İncesu C, Karakoç B (2008). The unconsummated marriage: its frequency and clinical characteristics in a sexual dysfunction clinic. Journal of Sex and Marital Therapy 34, 268-279.

Plaut SM, Rach Beisel JA (1997). Use of anxiolytic medication in the treatment of vaginismus and severe aversion to penetration: case report. Journal of Sex Education and Therapy 22, 43-45.

Praharaj SK, Verma P, Arora M (2006). Topical lignocaine for vaginismus: a case report. International Journal of Impotence Research 18, 568-569.

Ramli M, Nora MZ, Roszaman R, Hatta S (2012). Vaginismus and subfertility: case reports on the association observed in clinical practice. Malaysian Family Physician: the Official Journal of the Academy of Family Physicians of Malaysia 7, 24-27.

Rayan A, Fawaz M (2017). Cultural misconceptions and public stigma against mental illness among Lebanese university students. Perspective Psychiatric Care Journal 54, 258-265.

Reissing ED, Binik YM, Khalife S (1999). Does vaginismus exist? A critical review of the literature. Journal of Nervous and Mental Disease 187, 261-274.

Reissing ED, Binik YM, Khalife S, Cohen D, Amsel R (2004). Vaginal spasm, pain, and behavior: an empirical investigation of the diagnosis of vaginismus. Archives of Sexual Behavior 33, 5-17.

Safak Ozturk C, Arkar H (2017). Effect of cognitive behavioral therapy on sexual satisfaction, marital adjustment, and levels of depression and anxiety symptoms in couples with vaginismus. Turkish Journal of Psychiatry 28, 172-180. 
Seo JT, Choe JH, Lee WS, Kim KH (2005). Efficacy of functional electrical stimulation-biofeedback with sexual cognitive-behavioral therapy as treatment of vaginismus. Urology Journal 66, 77-81.

van Lankveld JJ Granot M, Weijmar Schultz WC, Binik YM, Wesselmann U, Pukall CF, BohmStarke N, Achtrari C (2010). Women's sexual pain disorders. Journal of Sexual Medicine 7, 615-31. van Lankveld JJ, ter Kuile MM, de Groot HE, Melles R, Nefs J, Zandbergen M (2006). Cognitivebehavioral therapy for women with lifelong vaginismus: a randomized waiting-list controlled trial of efficacy. Journal of Consulting and Clinical Psychology 74, 168-178.

Weijmar Schultz W, Basson R, Binik Y, Eschenbach D, Wesselmann U, Van Lankveld J (2005). Women's sexual pain and its management. Journal of Sexual Medicine 2, 301-316.

Zargooshi J (2000). Unconsummated marriage: clarification of aetiology; treatment with intracorporeal injection. British Journal of Urology International 86, 75-79.

\section{Learning objectives}

(1) To understand belief systems and behaviours linked to female sexuality and couple relationship in the Arab-Muslim culture.

(2) To draw attention to socio-cultural factors specific to Arab-Muslim culture interfering with therapy.

(3) To know how to adapt generic CBT techniques to the cultural specificities of these patients.

(4) To understand the importance of sex education and cognitive techniques for couple and family in the treatment of vaginismus in Arab-Muslim patients. 